\title{
The design process of a multi-disciplinary tool for developing interactive textiles
}

\section{Julia van Zilt \\ ITL STUDIO}

EINDHOVEN, THE NETHERLANDS

julia@itlstudio.com
Amy Winters

EINDHOVEN UNIVERSITY OF

TECHNOLOGY, THE NETHERLANDS

a.k.m.winters@tue.nl
Hannah Carlotta Kelbel

INSTITUT FÜR TEXTILTECHNIK DER RWTH

AACHEN, GERMANY

Hannah.kelbel@ita.rwth-aachen.de

Miguel Bruns

EINDHOVEN UNIVERSITY OF

TECHNOLOGY, THE NETHERLANDS

mbruns@tue.nl

\section{ABSTRACT}

Interactive textiles embed sensing and actuating capabilities in their fibers and structure. Adoption of interactive textiles is complex requiring a combination of competences or collaboration between interaction designers, textile designers and textile engineers. These disciplines are typically organized in separate and unconnected departments, using different vocabularies, and requiring different information. Through focus groups with interaction designers, and interviews with experts from the three domains we developed the Interactive Textile Library (ITL). The ITL is a multi-disciplinary tool combining physical samples and a digital platform showing material characteristics, experiential qualities, interactive technology, manufacturing process and support to create and hack the samples. The ITL was evaluated with professional designers who valued the physical samples and videos. Results provide recommendations for researchers developing interactive textile material libraries that could facilitate incorporation of interactive textiles in design practice and reduce fabrication time of prototypes.

Permission to make digital or hard copies of part or all of this work for personal or classroom use is granted without fee provided that copies are not made or distributed for profit or commercial advantage and that copies bear this notice an the full citation on the first page. Copyrights for third-party components of th work must be honored. For all other uses, contact the Owner/Author.

TEI '22, February 13-16, 2022, Daejeon, Republic of Korea (c) 2022 Copyright is held by the owner/author(s). ACM ISBN 978-1-4503-9147-4/22/02.
https://doi.org/10.1145/3490149.3502258

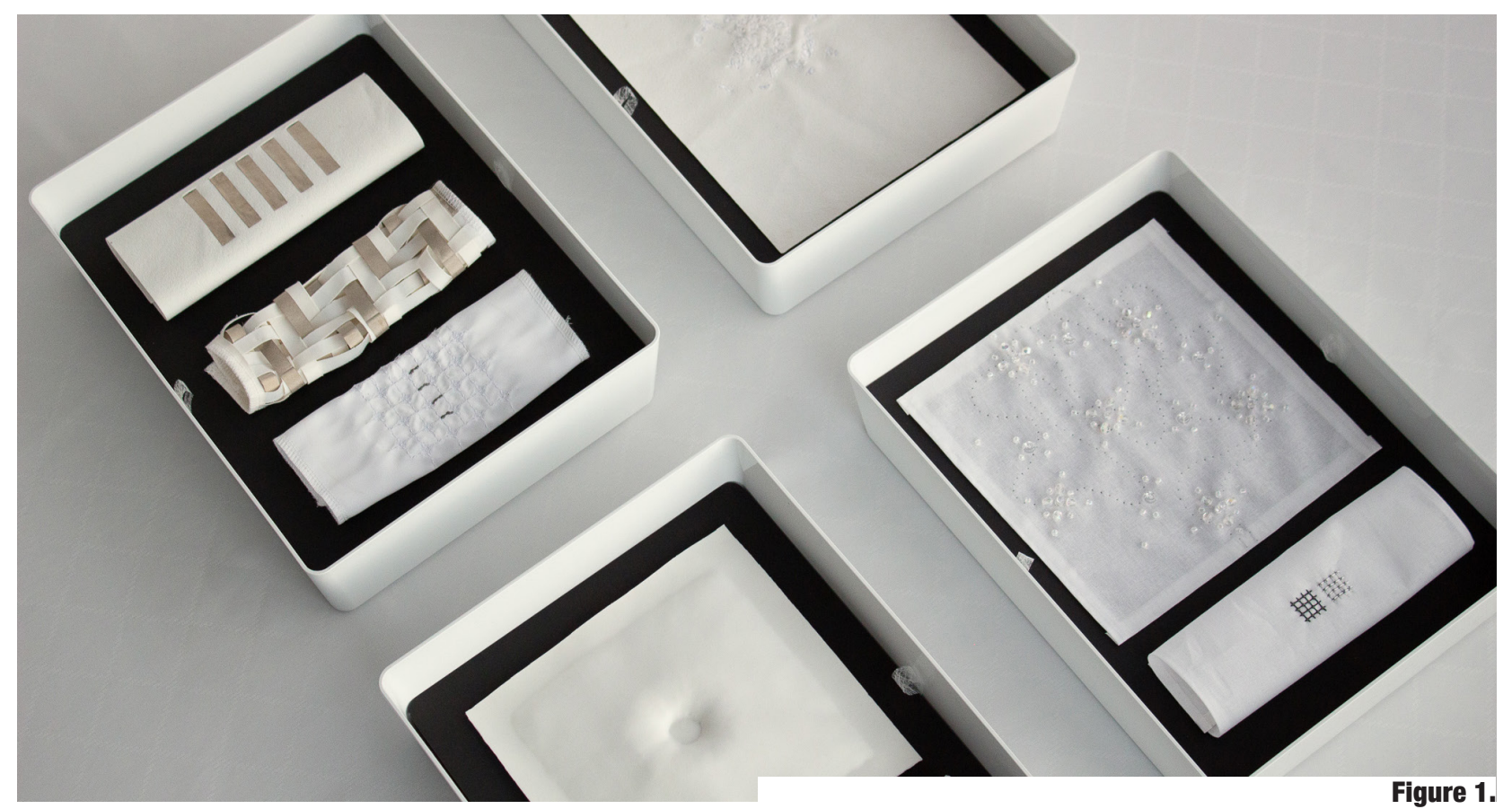

The interactive textile samples made for the Interactive Textile Authors Keywords Library as presented to the experts in the final evaluation Interactive textiles; Digital manufacturing; Research through design; Interdisciplinary collaboration; Prototyping cSs Concepts

- Human computer interaction (HCI) Interactive systems and tools User interface toolkits 


\section{Introduction}

There is an emerging type of textiles that combine sensing and/or actuation, and in some cases embedded computation in their fibers and structure. These textiles carry different names in different disciplines, e.g., smart textiles [65], textronics [39], intelligent textiles [37], e-textiles [22] etc. In this pictorial we refer to them as interactive textiles, as these textiles support interaction with users through their sensing, actuating and computational capabilities. Unfortunately, adoption of these interactive textiles is complex as it requires a combination of competences or collaboration between interaction designers, textile designers and textile engineers. These disciplines are often organized in separate and unconnected departments, they use different vocabularies and have varying information requirements. However, to fabricate functional interactive textiles ready for scalable production all three perspectives are vital.

The development of interactive textiles happens across the different mentioned fields and each of these perspectives focuses on developing these novel types of textiles within their own domain. Interaction designers create tools for others to incorporate interactive textiles within their design processes [49]; textile designers wish to advance the incorporation of experimental fabrication techniques from print, weave, knit and mixed media to create novel forms of interactivity [57]; while textile engineers investigate scalable solutions and optimization of the production processes of these textiles [22]. Some industries already investigate the use of interactive textiles such as the automotive industry (e.g., BMW's Vision iNEXT); the fashion industry (e.g., the work by Pauline van Dongen); or the healthcare industry (e.g., Lumalive by Philips). However, the presented examples often remain conceptual and are not adopted in everyday practice because these industries generally adopt more conventional approaches to interdisciplinary collaboration, following a hierarchical and departmenta culture, linear design processes where different departments and experts do not, or barely, collaborate on product development.

In the automotive industry, for example, interdepartmental collaboration happens for the development of specia projects such as the creation of a concept car, but under regular circumstances a department such as Color and Trim solely focuses on the material and colors of different elements within the car interior. As soon as anything electronic comes into play, the project is handed over to the Human-Machine Interaction (HMI), User Interface (UI) or Interior design department. Meaning that when integrating technology, vital knowledge of the materials in which the technology should be integrated is not taken into consideration.

To start bridging the gap between the different disciplines we contribute recommendations for researchers developing interactive textile material libraries through the development of a platform that supports the communication between the different types of expertise and stimulates multi-disciplinary collaboration. We start from interaction and industrial designers who develop the concepts and investigate how they can adopt more textile-led and textile engineering approaches, to support interaction between the disciplines. We propose the Interactive Textile Library (ITL), a platform that was developed by means of an iterative inspiration-based research through design process, in which literature, focus groups and interviews informed the design process [52]. The presented library (which is under continuous development) resulted from three phases. In each iteration we developed an initial probe, which was evaluated through focus group sessions with experts to determine the necessary communication elements for successful multi-disciplinary collaboration. During the final iteration an assessment of the platforms was carried out with experts from the three considered backgrounds, interaction design, textile design and textile engineering. We first discuss the design approaches and state-ofthe-art in each of the disciplines, the three phases of the project, including a description of the platform and outcomes of its evaluation with experts. We conclude with a discussion on the Interactive Textile Library and the implications it has for designing interactive textiles across disciplines.

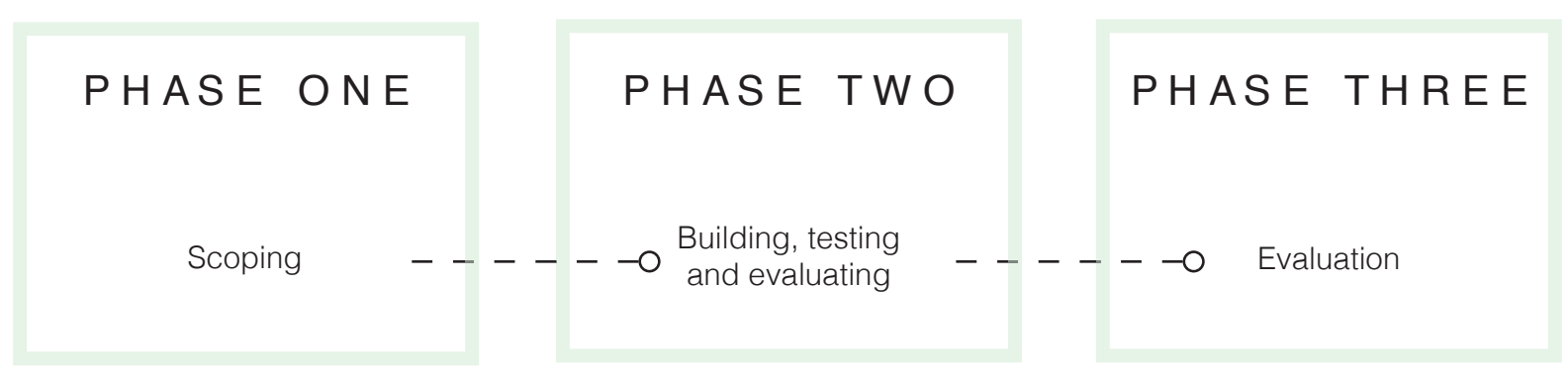




\section{Challenges and approaches from three perspectives}

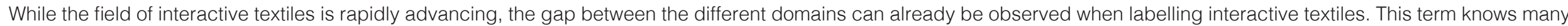

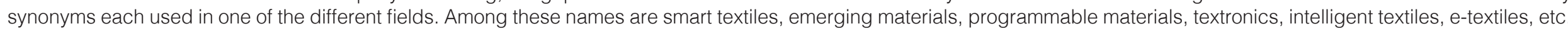

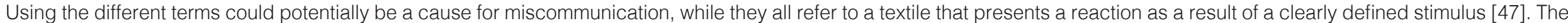

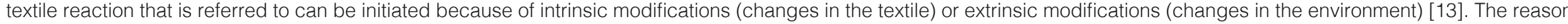

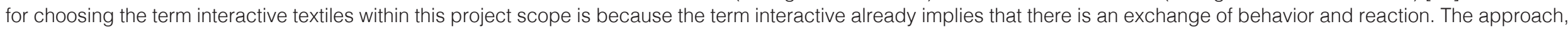
focus and current state of the art of the different disciplines with regard to the development of interactive textiles are described below.

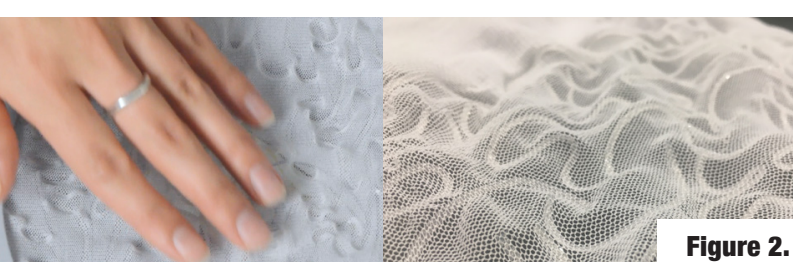

The interactive textile sample Breeze. Organic pattern 3D printed onto mesh fabric and actuated by electromagnets.

02.1INTERACTION DESIGN

With developments in tangible interaction, and particularly the more recent material turn in $\mathrm{HCl}$ [62] textiles are increasingly being used to bridge the gap between material science and interaction design [45] Textiles become especially relevant when researchers explore multimodal approaches to interaction that require more dynamic behavior to communicate information such as computational composites [60] or shapechanging interfaces [46], combining different layers of sensors, actuators and materials. Researchers in $\mathrm{HC}$ develop toolkits to support designers in prototyping these interfaces, investigate their user experience and possible applications.

Various design approaches can be distinguished in interaction design for example when generating novel textiles, material-driven design approaches [9] are often undertaken. Such approaches are characterized by material tinkering and experience prototyping [10] which take material as something open and unfinished instead of something that can be applied in the design [9]. By using participatory and user centered-design approaches, designers ideate and explore potential applications using the early material prototypes.
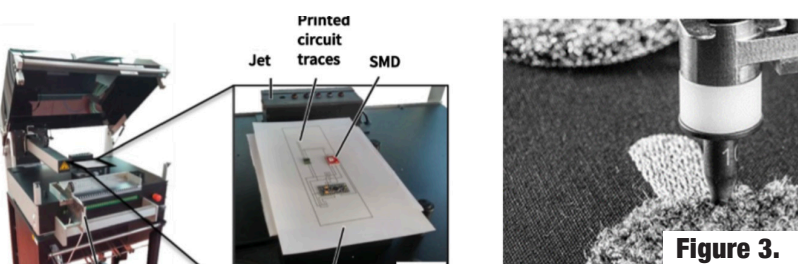

Left: Screen printing with Pick\&Place machine (Tenner 2017), right: Moss embroidery with sensors (ZSK Stickmaschinen GmbH 2021)

\subsection{TEXTILE ENGINEER ING}

In textile engineering, the entire life cycle of the developed textile is considered, including mechanical, chemical and thermal treatments such as washing, ironing, tumbling stretching and abrasion. As a result, engineers are often reliant and dependent on the capacity and capabilities of existing machines. Interactive textiles received considerable attention from engineers and the market but assistance to integrate is needed. Currently there is a strong interest in developing scalable manufacturing systems owing to prohibitive and uneconomical methods of integration in traditional production facilities.

In engineering the design approach usually follows a systematic approach to design and development such as VDI 2221. In this waterfall process, first requirements are defined which are turned into feasible solutions [4]. For the design of 4D-textiles Schmelzeisen et al. [53] suggest an integrated process consisting of three steps (Understand, Create and Develop). The process starts by defining a user centered problem, followed by a prototyping process and concludes with a mechanical testing phase. It aims to combine multiple perspectives including the SCRUM procedure from information engineering.

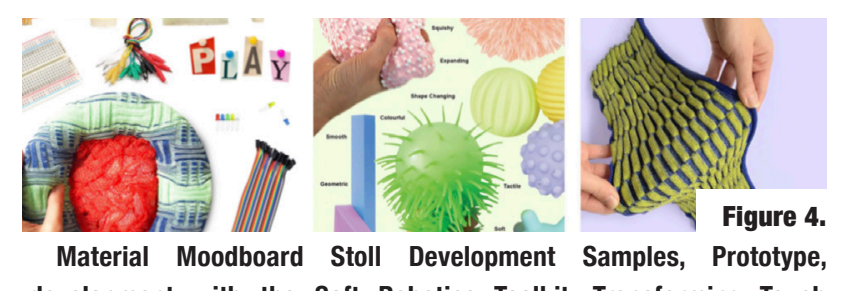

development with the Soft Robotics Toolkit. Transforming Touch Michelle Rinow. Photograph by Harris \& Ewing

02.3 TEXTILE DESIGN

Textile designers use a technical and poetic vocabulary of materials [55], combining performance properties with physical and visual qualities such as, "sensory perception, aesthetic and haptic pleasure" [27]. By connecting textiles and temporal form, intricate textile designs are turned into a layered collection of interactive expressions [64], using color, texture, and pattern to create sensitive and expressive interfaces [55]. Textile designers focus on the material's aesthetic and tactile expressiveness while also translating technical characteristics into novel contextual uses, contributing to the enhancement of physical and visual experiences in interactive textiles [27]

The 'textiles thinking' $[27,63,52,55,28]$ design process considers aesthetic, cultural and functional properties expressed through colors, shapes, patterns and forms Textile designers are driven by physical prototyping, with a strong multisensory component (visual, tactile, olfactory). They use textile design mood boards, to identify sensory properties, e.g. 'squishy', 'expanding', 'smooth', 'fluffy' through materiality using open-access toolkits [29] which provide designers with the necessary technical know-how to produce new materials for nuanced sensory experiences and tactile interfaces. 


\section{Related work from three perspectives}

The use of textiles when designing shape-changing interfaces has been explored in applications such as furniture [38], automotive [17] or fashion [58]. A recent study by Qamar et al. [44] presents a review of advances in material science with their properties and behavior and discusses how these can be applied in this context. Many of these properties have been addressed using textiles including auxetics and kirigami [29], foldable structures [20], inflatables [66], shape-memory materials

[18]. In addition to shape-memory alloys, more advanced integration of shape-memory and textiles have been used in combination often with 3D printing [49] e.g. hydrogels [48] or bacteria [60]. More recently, roboticists have recognized the capacity of textiles as a 'material platform' [51] whose underlying structure and composition act as both a sensing and actuating mechanism.

A design space opens for the production processes from textile engineering and design to support interactive textiles and new forms of textile robotics. Textile surfaces such as weaves, warp, weft knits or nonwovens out of various materials are used as base for smart textiles. Conductive fibers are either intrinsically (metal, PANI PPY) or extrinsically (carbon nanotubes, metal particles) conductive, coated or offer a combination of the mentioned yarns [22]. For industrial purposes conductive polymers or metal-coated yarns are used. In addition, classic electronic components such as LEDs [29] or microelectronics [15] are incorporated for electronic functionality. These can be fabricated through printing methods, e.g. conductive metallic inks (silver, carbon, graphene) for soft, stretchable circuits and capacitive sensing.

Current production processes can be separated by textile surface processing and subsequent integration. Conductive, shape changing, or light emitting yarn is processed within the actual textile production process either in knitting through textile surface processing [18,38,39], weaving [14] or spacing textiles [8] Subsequent integration functionalization is achieved by embroidery or printing with coatings $[29,42]$. To ensure the connection between textile and electronic components reversible adhesion (e.g. snap fastener) is used whereas for irreversible contacting adhesive bond (e.g. soldering) or form closure (e.g. stitching) is used [21], which is then connected to a computing system. Fiber-optic fibers can be woven for light-emitting purposes (Luminex) or used as a sensor to calculate tensile and compressive forces to detect the human body's movements [27] without using solid-state sensors.

03.1 SWATCHBOOKS, LIBRARIES AND TOOLKITS

Previous work on interactive textiles has investigated the use of swatch books, i.e., collections of samples or pieces of fabric, to support designers in working with these technologies. For example, the Textile Interface Swatchbook specifically focused on the use of conductive embroidery and this technology was used to create "GUIlike widgets that can control mobile devices" [23]. On the other hand, Hertenberger et al. [25] was a collaborative effort by various researchers to build the E-Textile Swatchbook. The result is a book composed of 24 swatches developed by each researcher, based on the technology provided by the other researchers attending the eTextile Summercamp. Textiles samples have been defined in $\mathrm{HCl}$ within multiple contexts from affordances [41], textiles interfaces [41], dynamic displays [16] interactive fashion design [58] and craft [32]

In addition to swatch books, libraries often present collections of artefacts and aim to share knowledge to understand, contextualize or reproduce such. Research and industry often use this format to publish and share their findings, e.g., materiability [3], soft robotic toolkit [5] or Morphui [50] Material Connexion [47] ] These platforms typically require certain expertise to understand, use and reproduce the presented content. $A$ reliable and clear platform normally follows a consisten and structured layout throughout the entire library. Such formats are also used by maker communities such as Kobakant [2], Adafruit [6] or Materiom [1], which are characterized by detailed tutorials aimed to inform users on how to reproduce the presented content, using nonexpert language making them accessible to a wide audience. Accessibility, consistency, and reproducibility are consequently important features to consider when wanting to communicate content and appeal to both experts and non-experts.

Toolkits are mostly used by product designers and textile designers, and we identified two main aims

Production focused innovation aims to improve the process in terms of assembly and fabrication of electronic textiles or soft interfaces. Solutions are often presented in the form of platforms or programs such as Tee-board which is designed to ease the integration of e-textiles in educational computing [42]; Sketch \& Stitch which translates a colored-hand drawn circuit into an embroidery pattern [22]; or AdaCAD, a crafting software for circuit integration within the weaving process [20]. On the other hand, we see different production technique developments to for example to support the integration of 3D printing with textiles [49] or inspire the integration of certain fabrication techniques such as inflatables [43]

To aid the design process modular concepts are developed to facilitate rapid prototyping and fas implementation of interactive textiles. The different concepts include Swatch-bits, an ideation and prototyping tool(kit) that contains e-textile swatches that function as connectable bits [28]; Quilt Snaps, which is designed for children to take on a role as engineer, designer or decorator [12] and is a construction kit consisting of pieces made from computationally enhanced quilting pieces. LilyPad Arduino is a tool to build e-textiles consisting of stichable sensors and actuators [11]

"In textiles history the term "samplers" has been used to describe piece of needlework exemplifying a skill or craft. However, we decided to employ the word textile samples, as it is our aim to bridge the gap in-between disciplines using non-expert language. 


\section{Summary of requirements}

In this section we outline five design requirements, which we based on the works specified above.

\section{Consistency of layout}

Consistency throughout the platform allows for easier navigation and more targeted access to content. The same type of information should be provided for each interactive textile in the same order and location. Morphui. com [50] is an example of a platform supporting the design of shape-changing interfaces and morphing materials that presents scientific papers on different related topics following a fixed format per discipline.

\section{Expert specific information}

Depending on their expertise, users will have different needs regarding the information about interactive textiles. Therefore, information must be accessible to all three types of expertise. Most platforms require expertise in at least one specific field. For example, to understand and use the Soft Robotics Toolkit [5], a basic understanding of electronics is required.

\section{Tutorial based explanations}

For reproducibility and a better understanding of the fabrication process of interactive textiles a tutorialstyle explanation on how to fabricate it should be provided. Materiom.org [1] presents a material library providing a step by step information on how to make certain materials.

\section{Modularity of components}

To support further development of concepts with or of interactive textiles, interconnectable components should be offered. Learn.adafruit.com [6] is a tutorial platform which uses standardized electronic components, compatible with Arduino, in all their projects.

\section{Industry applications}

Aiming to bridge the gap between research and industry information regarding possible application domains should be specified. Materiability.com [3] project pages show possible applications of their developed techniques.

\section{Method}

To develop the multi-disciplinary tool, a three-phase inspiration-based research through design approach was followed [52]. Probes were used to explore, co-create and validate, building upon the experience and inspiration of designers. The aim of the first and second phase were to build an eventual prototype of the multidisciplinary tool. This was carried out through focus group sessions in which participants were presented with two (during the first iteration) or one (during the second iteration) probes. The probes were introduced; experienced by the participants; and lastly discussed in a semi-structured interview. The findings of these focus group sessions were recorded through written annotations and digitally annotated responses by the participants. The annotations were summarized, organized and categorized using thematic analysis of the different topics and insights, from which the most important insights were deduced. The aim of the third phase was to assess the final prototype of the multi-disciplinary tool. These sessions consisted of an evaluation through a questionnaire and a semi-structured interview. The participants were different experts, each from a different field of expertise; one textile designer, one textile engineer and five interaction designers.

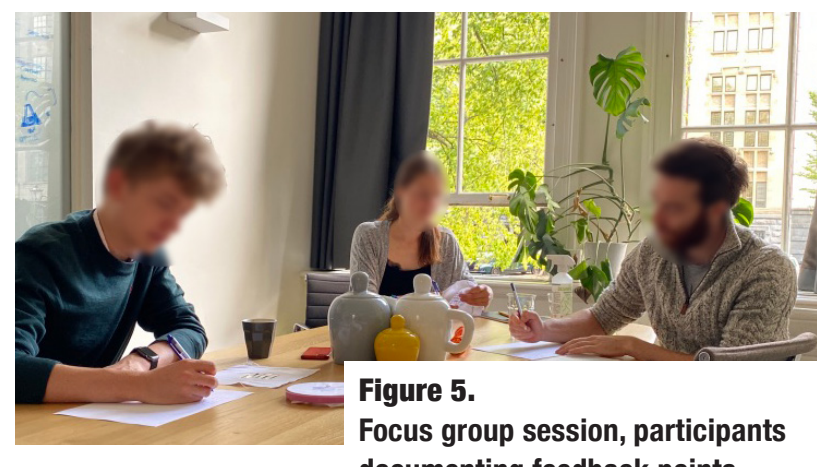
documenting feedback points.

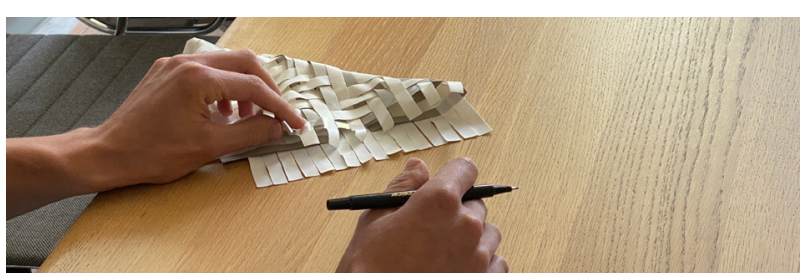

Figure 6.

Participant of the focus group session interacting with the samples

\subsection{PARTICIPANTS (phase one)}

In all three iterations interaction designers were involved. All interaction designers have a background in interaction or product design and worked at a design consultancy for multinational clients in the automotive (Mercedes Benz, TomTom), electronics (Dell, Intel, Oppo, Philips, Samsung) and performance fashion (Nike) industry. During the third phase, researchers in textile design from the London Royal College of Art and textile engineering from the Institute for Textile Technology at RWTH Aachen were involved.

Aiming to support the application of interactive textiles in industry, interaction designers were selected due to their knowledge regarding the design and application possibilities of not only soft interfaces but also digital interfaces. Textile designers have expertise in creating aesthetic textiles but their knowledge regarding interaction with users is often limited. Their strengths include the direct participation with users in the design for their specific contexts such as fashion or healthcare. Textile engineers have knowledge regarding the production techniques and the scalability of textiles but need assistance in the integration of textiles in products or to make them aesthetically appealing to users. 
The aim of phase one was to define the relevant information and textile content. During the first focus group session two probes were presented. The first probe consisted of a digital document showcasing an image of the interactive textile in use and some of its interactive features.

The second probe consisted of five textiles that were enhanced with interactive touch elements. The aim of this phase was to start curating the relevant content both digitally and physically. The session with the interaction designers consisted of three parts. First, a general introduction of the project concept was given using slides with visual aids. Secondly, a textile probe was given to each participant, who was free to explore the sample and asked to document the information which they considered to be missing. Finally, an open-ended discussion took place addressing what information and in what way the information could best be provided (digitally or physically) to efficiently and effectively use the samples in their design practice. The session concluded by discussing what type of actuated textiles would be of relevance for them and the industry they operate in.

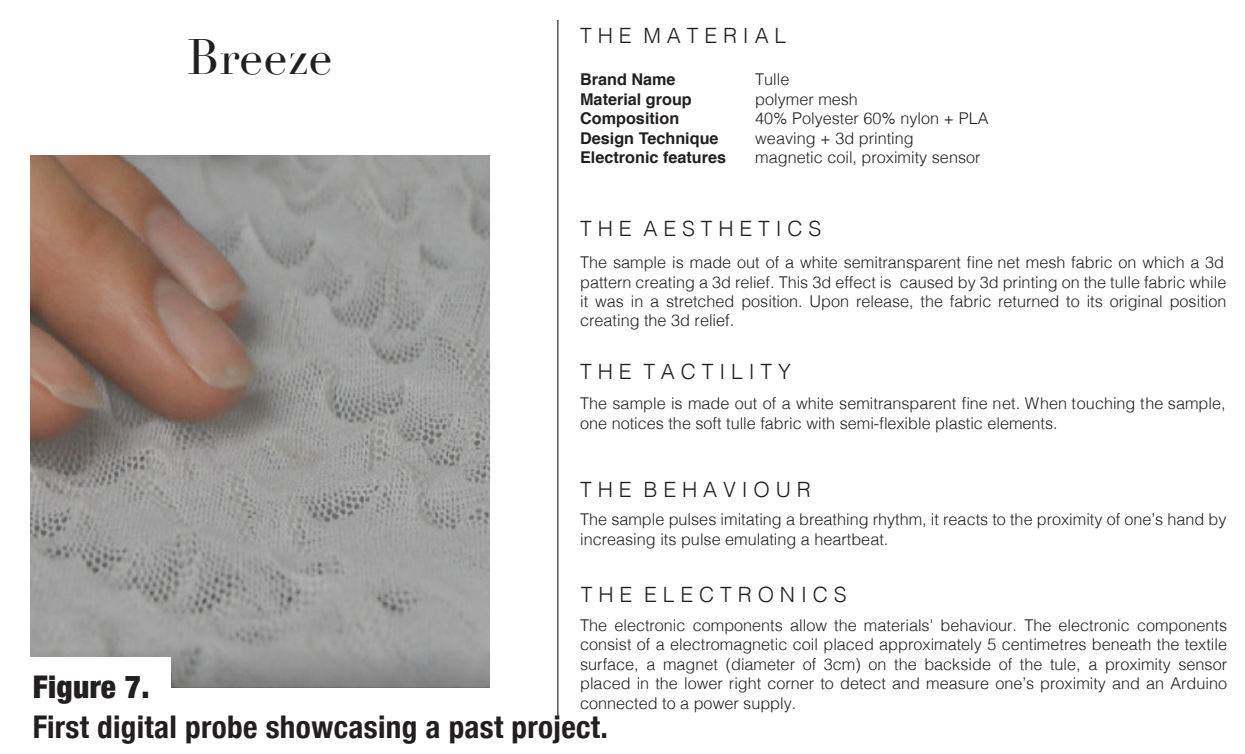

Figure 8.

Second probe, consisting of a collection of 5 physcial textile samples. A) Embroidered grid with one direction touch detection B) Organice textured embroidery pattern C) Slider made out of conductive fabric D) Woven slider made out of conductive fabric and leather-like fabric E) Embroidered slider pattern

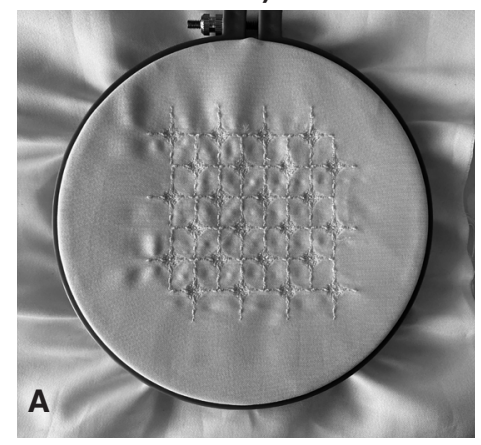

05.2.2 RESULTS

he interaction designers were able to engage actively both in the assessment of the probes and the speculation of future possibilities. They showed interest in implementing the textiles and concepts within their own design processes. The outcomes of the annotations and responses can be divided into two subcategories: digital versus physical information and content of the library.
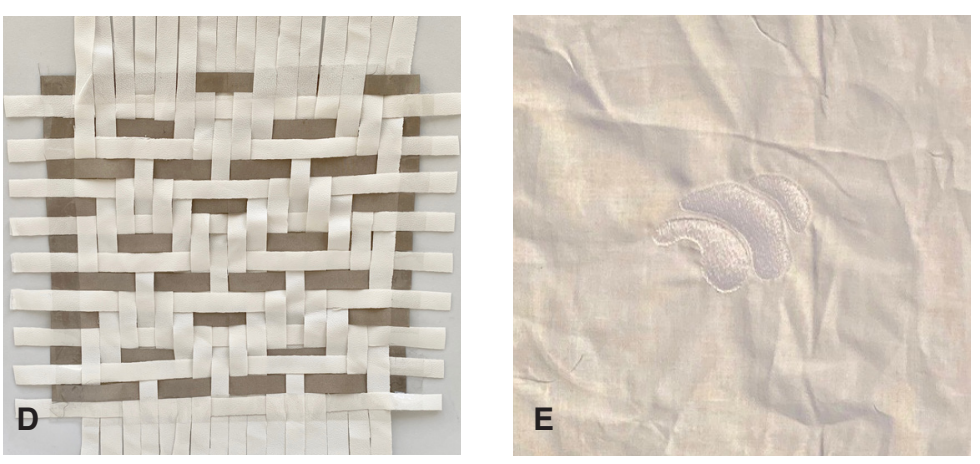

Digital versus physical information. According to the participants all information about the interactive textiles should be presented digitally. Depending on the relevance of the information there should be a visible hierarchy, meaning that not all information should be visible at the same time or at all times. To understand the interactive textiles presented they required more visual aids, preferably in the form of videos, which should then inform how to interact with the sample and what its inherent characteristics are. Physically they only required the textile itself and a link to the digital information, for example in the form of a QR code. 
The interactive textile. This section could be divided into two subsections:

Material information: Passive textile information such as flexibility, permeability, durability, etc.

Active information: the designers found it particularly interesting that the library described what exactly the material could do and could not do. They later mentioned that they would also like to be told how to explore the material. This general information would be needed to understand how the sample could be used in their projects.

Hacking the sample. Designers continuously adapt technology and materials to what their project needs. Consequently, this is one of the sections that was most important to the designers because it has impact on their time efficiency and limitations or possibilities of their own creativity. From the different conversations, we observed that to customize the samples they would first need to fully understand how it could be reproduced. This was very importan to the interaction designers because they would want to integrate the knowledge that ITL offers within their work and understand how to build and change the sample is the foundation of that.

Random. The fourth section included a diverse range of interests, including legal information and an outlook on future ITL developments.

05.2.3 BUILDING, TESTING AND EVALU A TING (phase two)

The aim of phase two was to evaluate the improved version of the first digital probe. The different criteria that were established during the first focus group session were used and translated into the layout design of the digital online platform. This platform first showcased a general overview of the different textiles on the dashboard. From the previous session we extracted the following criteria:

- Hierarchical layout of information

- Visual aids

- Hacking the sample

During the focus group the second probe was presented in an online session. The session was split into three sections:

Figure 9.

Digital probe: First full platform layout part 1

Capacitive touch collection

\section{WOVEN TOUCH SENSOR}

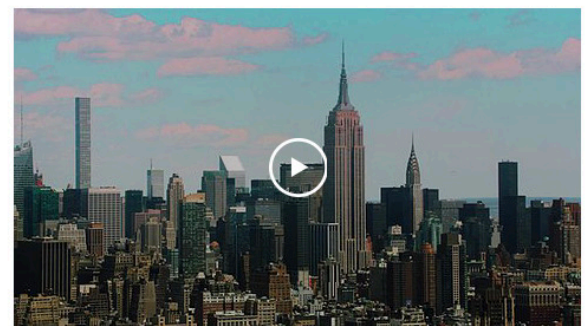

Fabrication Difficulty $\bullet \bullet ० ० ०$

Customizability

$\bullet \bullet \circ ० ०$

Time to fabricate: $\mathbf{1 h}$

Main fabrication method: weaving

Main technology: non-woven conductive textile

Main material: non-woven conductive textile

Fabrication machines necessary: Hand- or

machine weaving

INTERACTIVE MATERIAL

FEATURES

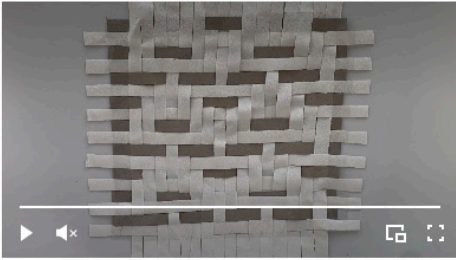

THE INTERACTION

The material responds to touch and can detect the direction of touch. The structure is big enough to interact with one's hand and one's finger.

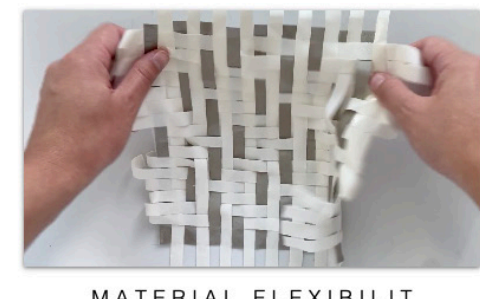

MATERIAL $\underset{Y}{F L E X I B I L I T}$

The textile is extremely flexible, it can be compared to a regular thin non-woven synthetic

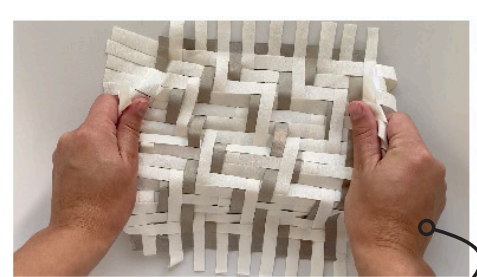

MATERIAL STRETCH On the $y$-and $x$-axis the woven fabric is no

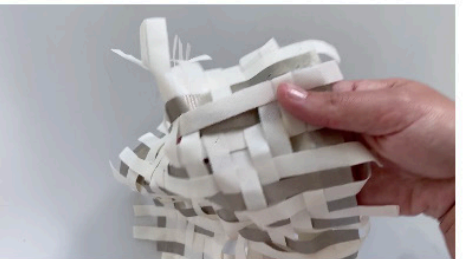

MATERIAL OPACITY

It is not see-through except for the holes in between the interwoven textiles. very stretchable. Diagonally it is very flexible
Hierarchical layout of information. This was implemented by providing three different viewer options depending on the user's expertise. Within each mode general overview of key features per expertise was followed information. by more detailed textile.
Visual aids On the designer viewer mode videos were shown to inform the user about the interactive features of the textile. 
Introduction and closer look to our experts. Several questions were asked about what type their expertise, how they are inspired, where they search for new information, what they look for when they search for new materials to implement in their work and what other experts they collaborate with.

Online tool evaluation. This was carried out per page: homepage, dashboard, and textile page. The users were asked to navigate through the pages and were asked to place comments on the parts that attracted them most, least and what they would click on.

Value propositions. Lastly, an open-ended discussion took place regarding the value propositions of the platform in its current form for their industry.

\section{Figure 10.}

Digital probe: First full platform layout part 2

\begin{tabular}{|c|c|c|}
\hline JVERVIEW & COMPONENTS & ADDITIONAL T \\
\hline $\begin{array}{l}\text { 'ower usage: } \\
\text { 'rogramming software: } \\
\text { jomething else: } \\
\text { Jog iets else here: }\end{array}$ & $\begin{array}{l}\text { - Teensy } \\
\text { - Something else } \\
\text { - Component nr } 1 \\
\text { - Component nr } 1 \\
\text { - Component nr } 1 \\
\text { - Component nr } 1 \\
\text { - Component nr } 1\end{array}$ & $\begin{array}{l}\text { - Soldering machine } \\
\text { - Wire cutter } \\
\text { - Plyers } \\
\text { - Component nr } 1 \\
\text { - Component nr } 1 \\
\text { - Component nr } 1 \\
\text { - Component nr } 1\end{array}$ \\
\hline
\end{tabular}

CONNECTORS

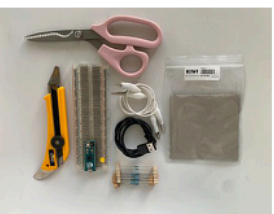

\section{TECHNOLOGICAL FEATURES}

Figure 11.

Digital probe: First full platform layout part 3

Material Name

Brand Name

Supplier

Composition

Alternatives
MATERLAL FEATURES

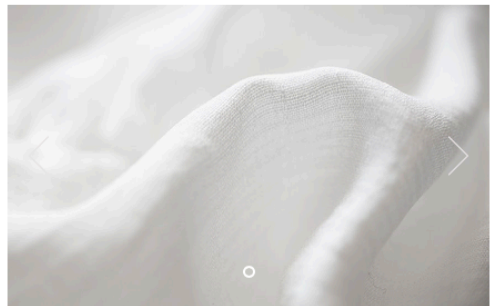

HOW TO RECREATE

r specified what and how one can change features of this interactive material
WHAT CAN I COSTOMIZE:

- The colours

- The non-woven textil

ave pattern
WHAT MACHINES DO I NEED? WHAT MACHINES DO I NEED? - Download these files into your Download these files into your own own Dropbox account, you will
always have the original files here have the original files here as well.

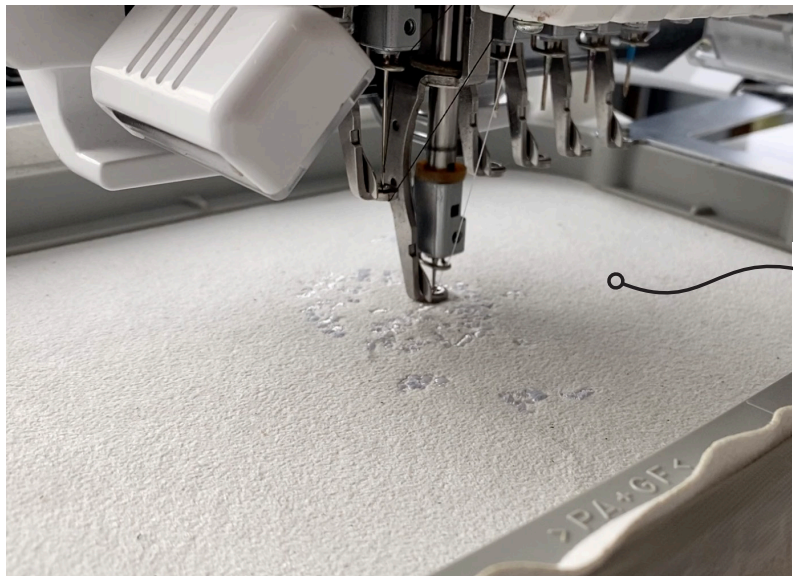

PROJECT FILES

Download these files into your own Dropbox account, you will always have the original files here as well.

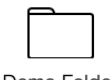

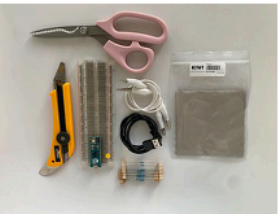

Placeholder images were used to give a general impression of the eventual content
SOMEHTIN

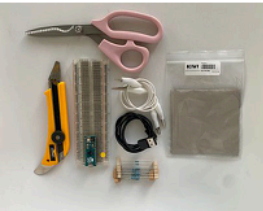

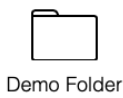

Hacking the sample. To support users in further personalizing and

developing interactive textiles a "how to recreate" section was added specifying the different tools and materials necessary to recreate the presented textile.

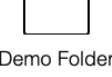




\section{Method}

Expertise. They mostly identified as product and/or interaction designers. An interesting aspect of this statement and the discussion that followed was that interaction design is often associated with digital design. By associating the term interactive, in this project, with physical materials supports reinforcing the importance of interaction design in the physical realm.

Finding inspiration. Usually, they search for inspiration in online platforms such as Reddit or they used Google as a search engine to find works that could help their current projects. An important aspect to note is that when they find something that inspires them, they look for features that they can prototype. Oftentimes their inspiration material lacks information such as the technology that is implemented or how it is produced.

Online tool. Overall, the response to the online tool was that it was a very useful tool. According to the experts it would fit different phases of their design process fulfilling different purposes. It was considered a source of inspiration because it demonstrates the different available materials and their potential use. The samples were considered a plug and play component that could be used during the first iterations of a design process, or an adaptable material that they could quickly make according to the criteria of their projects.

Homepage. The homepage sparked interest (to further explore the tool) through the video showing different snapshots of the production process of the interactive textiles. However, it did not clarify what interactive textiles exactly entail and what use cases it could be implemented in.

Dashboard. Due to the cluttered information presented on the dashboard the experts felt that there was no clear overview of the interactive textiles. In this version the textiles were shown through an image, this did not provide them with enough information and/or context. The main outcome of this discussion was that ideally only the textiles were visible, and more specific hints or tags could showcase the key features of each textile.

Textile page. All participants were enthusiastic about the features of the textile page. They were specifically fond of the standardized layout for each sample because once one is acquainted with the tool it is easy to navigate through the different samples and find the desired information. The videos made the interactive features evident, clear and usable to the designers. Improvement points included a clear description of what materials the textiles were made of and different use cases showcasing their potential.

Value propositions. When discussing the value of the tool for their industry three specific points were defined:

- ITL would help them "find the latest experimental textile explorations"

- ITL would help them "find the quality they need to create reliable exploration/prototypes" - They would be able to quickly prototype with a broad variety of materials and diving into the pros and cons without having to be specialists
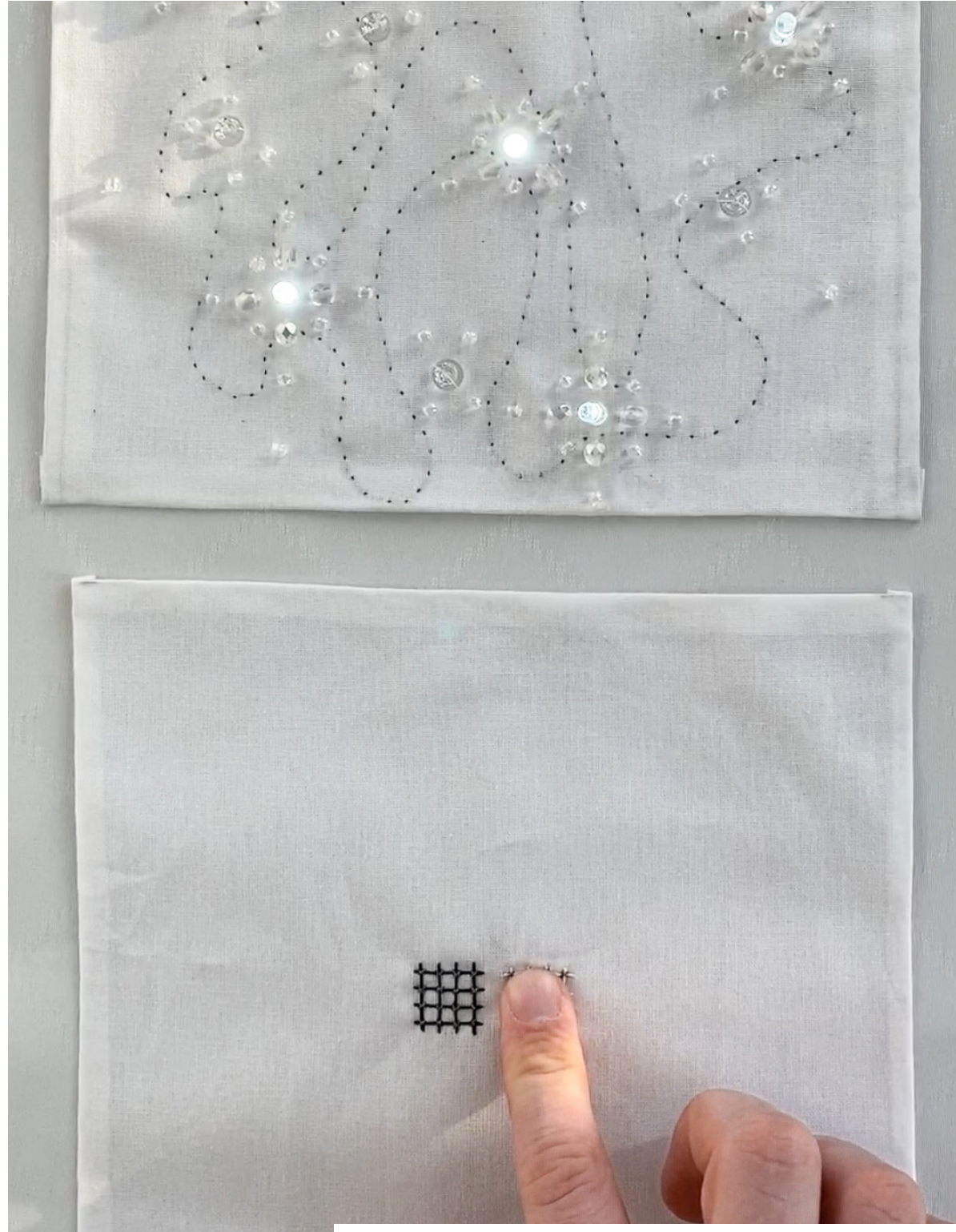

Figure 12

Two samples: Embelished Light and Textured Touch from the ITL platform connected and activated 


\section{The final prototype}

During the design process we were able to complete the criteria established by previous works. Based on these criteria and through the design process we developed a final prototype for the multi-disciplinary collaboration tool. The Interactive Textile Library (ITL) is an online tool aiming to support multi-disciplinary collaboration in the development of interactive textiles. This is achieved by offering information about an interactive textile from three different expertise perspectives. The digital platform consists of an online website containing a library-like layout showing the different available textiles. On each interactive textile page three different perspectives are shown between which the user can navigate. Each expertise page offers the appropriate information. To provide content and context on the online tool six textiles are presented both physically and on the digital platform. In the current version, four textiles are sensors and two are actuators, which generate output in the form of light. The sensors can be connected to the actuators showcasing an interactive textile. The techniques in the samples used are relatively simple compared to the current state-of-the-art, but for this project the samples served as placeholder content and should be understandable to all expertise levels (beginner to expert).

INTERACTION DESIGN

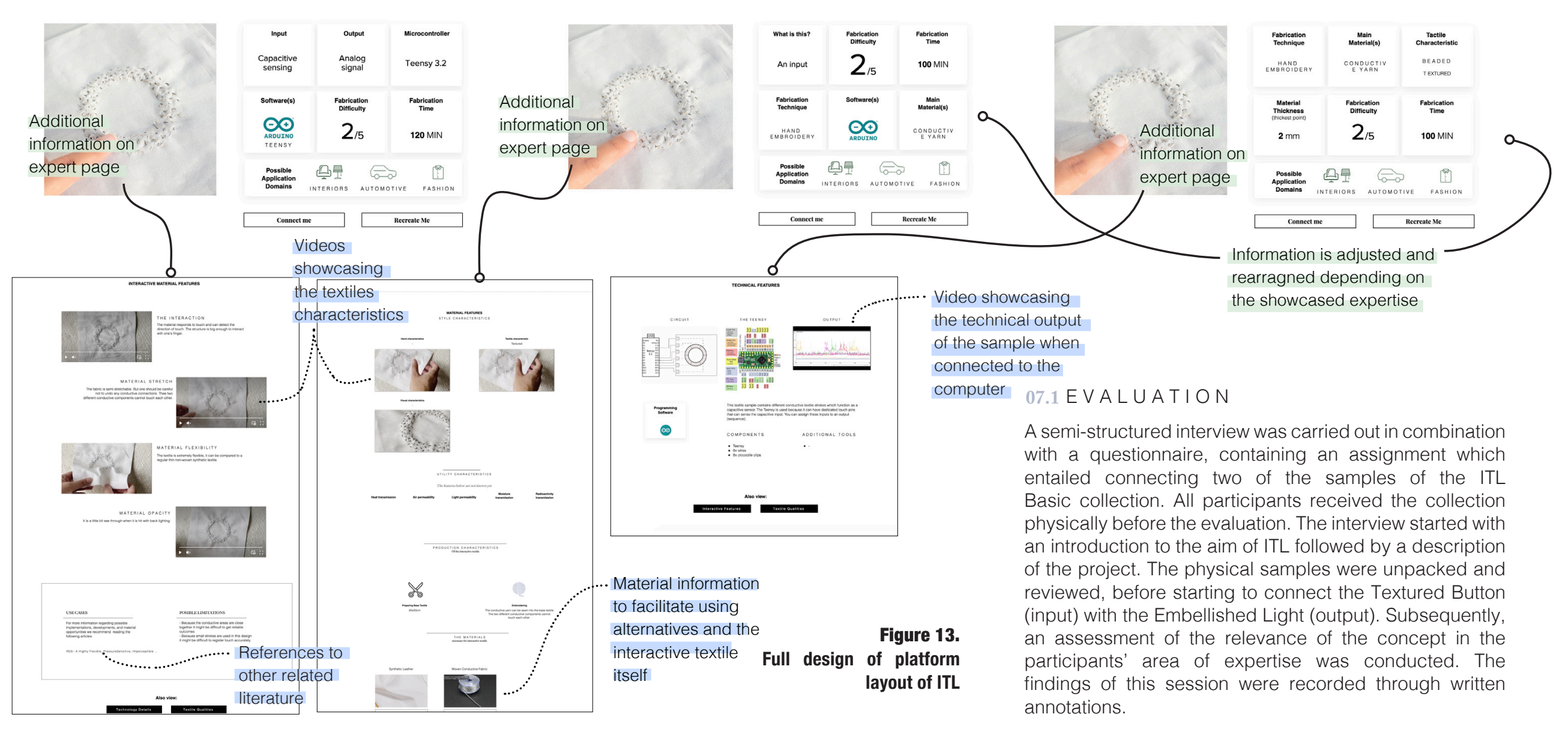

ENGINEERING
TEXTILE DESIGN 


\subsection{RESULTS}

The results of the final evaluation were divided into the categories samples and platform.

Samples The textile samples were received with excitement by the participants. Most wanted to further use, explore or "hack" the presented samples. There was some divide in the perception of the fidelity of the samples, opinions ranged from a first prototype to a Home Décor ( "Zara Home") product. Even though a step-by-step guideline was presented to connect the electronics to activate the samples, difficulty was experienced by the textile designer when having to connect the electronics to activate the samples. This was due to some expert language that the textile designer was unfamiliar with.

Digital platform The digital interface and its content added more depth to the presented textile samples. All experts were interested in their own domains first, but they all started to explore the other expertises too. They mentioned it would be useful because it would help to understand the perspective of fellow collaborators in multidisciplinary teams. The two features that were best received were the references to literature and the videos showing interaction with the textiles. Participants mentioned that this would support them in spending less time on trying to figure out the samples, and it would allow them to work more efficiently.

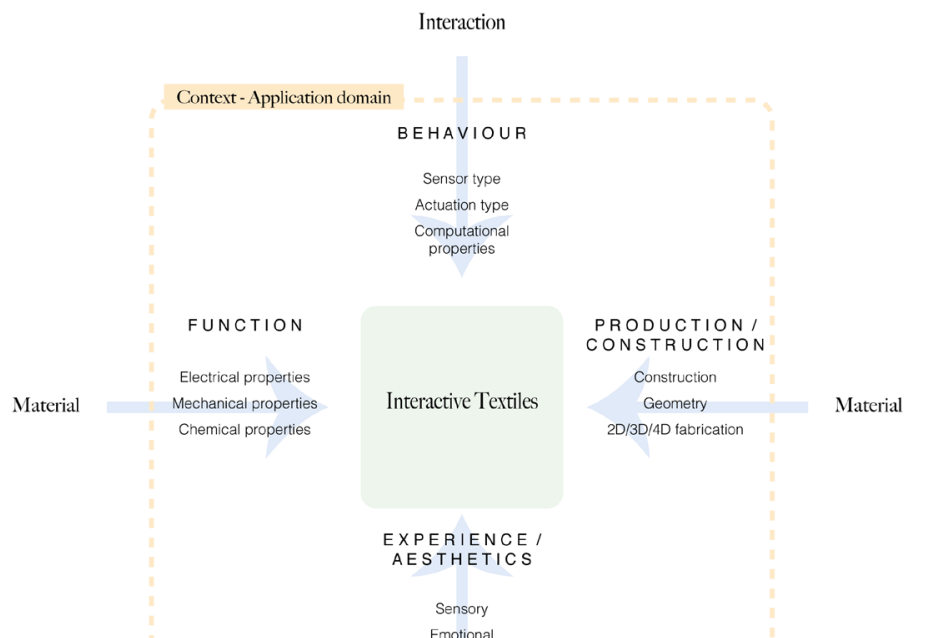

Figure 14.

Model relevant aspects of interactive textiles
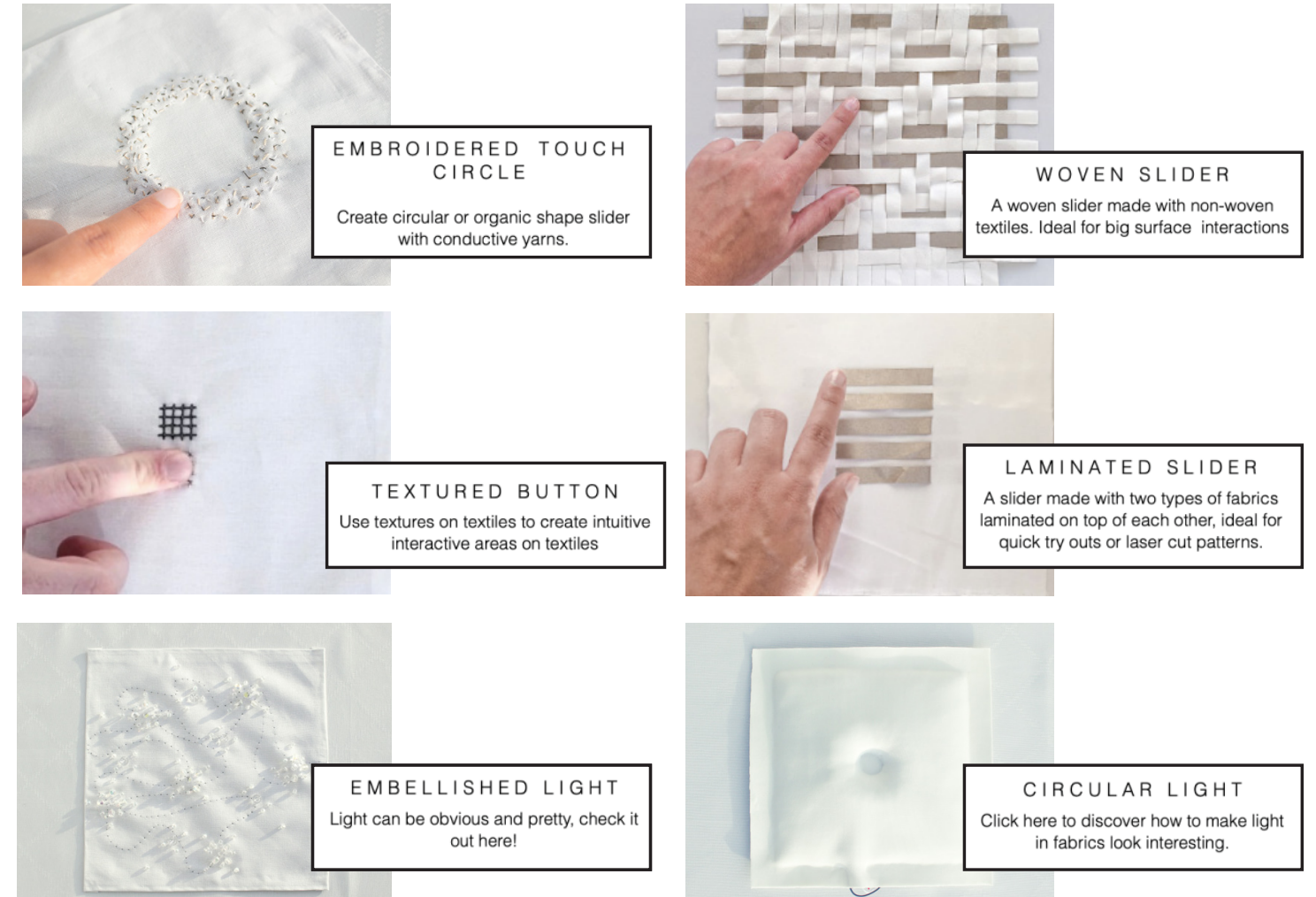

\section{Discussion}

This study defined guidelines for the development of a multi-disciplinary platform to support the development and implementation of interactive textiles. We implemented these guidelines in the design of ITL, providing discipline-specific information regarding modular interactive textile samples. Experts claim that by categorizing information by expertise and using corresponding language and terminologies they could quickly understand the presented textiles. Additionally, the ITL supported in gaining insights into the perspectives of other collaborators, and functioned as an interdisciplinary translator. Generally, ITL could be considered a communication tool clarifying the physical components using an accessible digital platform.

Similar to platforms like Materiability [3], the Soft Robotics Toolkit [5] and Morphui [50], a certain degree of expertise is required to optimally use of the presented content. However, by providing expert specific information from multiple perspectives, the textile information becomes usable to a wider audience. When evaluating ITL we noticed that providing both a physical and digital format, offered added value, in comparison to other formats. ITL differentiates itself from platforms like Kobakant [2] by providing expertise specific information in a fixed format, and from projects such as Google Jacquard [ref] by offering ready-made samples which can be 
easily recreated. Furthermore, while other toolkits mostly focus on supporting the prototyping process $[11,49,12]$, the ITL supports design from a material perspective, much like the textile thinking [56], material-driven design [9], and experience prototyping [10] approaches. Thereby supporting interaction designers to produce outcomes closer to actual industrial implementation.

During the design process we considered the perspectives of interaction designers, textile designers and textile engineers, particularly addressing possible applications, material properties and production requirements respectively. Together these disciplines cover a wide range of the development of interactive textiles. From constructing textiles, evaluating features such as washability or scalability, determining aesthetic features that inform interaction, to the implementation of interactive textiles into products. When designing the information flow, textile design and textile engineering features were mostly clustered as participants prefered to see all textile specific information in one place.

While designing the library and through discussions with experts, electrical engineering also became important, due to the electronic nature of the samples. Consequently, providing information about microcontrollers, programming software, etc. is required for further development. Other requirements that were defined throughout the design process included the need for visual aids through videos, to support participants in exploring the textile confidently; and providing application examples. In the ITL, application domain suggestions and related literature were provided.

The ITL was mostly valued by textile engineers as a communication tool. The different perspectives and related information were considered as an opportunity to identify their collaborators' needs. For textile designers the ITL offered an opportunity to enhance future textile designs with interactive features. The platform provides support regarding electronics and to find possible applications for these materials. To fully support this, more examples regarding application concepts need to be shown. However, one could argue that providing less references to other implementationsmay spark creativity. Interaction designers were keen on hacking the samples and parametric textile design could support quick customizability and prototyping.

An important feature included combining physical samples with a digital platform, emphasizing the interactivity of the textiles. The textiles instantly triggered all participants to explore the physical samples and discuss design possibilities before further accessing the digital information. The technical and aesthetic quality of the samples supported in determining their value with respect to experts' work. The multi-dimensionality of the digital platform is now insufficiently reflected in the textile samples, leaving room for technical improvement.

Toolkits are widely accepted in interaction design [e.g., 42, 11, 28] and textile design [e.g., 59, 27]. However textile engineers are not too familiar with toolkits and may be skeptic about such concept. Therefore, we opted for the term library, which is more widely accepted. We see opportunities for libraries to be used to support multi-disciplinary collaboration and to guide it by navigating design teams through the different stages of the development process and the required expertise at each stage. As a first step, we created an overview of different relevant aspects of interactive textiles (see figure 14). The model is adapted from the framework representing the different aspects that relate to the material choices in architectural projects [61] and aims to present an overview of qualities and expertise.

\subsection{I M I T A T IONS \& FUTURE W ORK}

We identified and validated the needs of three different types of experts for the design of a multi-disciplinary tool for using interactive textiles in the design process. Future work aims to identify how such libraries will work in practice by including multiple expert domains. In addition to the interaction designers, textile designers and engineers we also plan to involve electrical engineers to obtain a complete range of input. More complex and refined testing is required to improve and evaluate usability, accessibility, and relevance. For example, textiles as a subject encompass a variety of subdisciplines (weave, knit, print, and embroidery) which could approach and interpret these tools differently, and may thus result in different outcomes [59].

At times, some participants did not fully comprehend certain content when looking at the other modes. To improve this libraries should become both more simple and complex. The language implemented in the step-bystep guide to connect the different textile components used relatively simplified terminology, yet domain specific terms such as Arduino or microcontroller were not directly understood. This could be solved by adding a definition feature allowing users to gain a better understanding.

Although the generated insights can be applied to a broader context of interactive textile developments, the first author also aims to further develop the ITL to provide more advanced interactive textiles for industry, individual designers, or product-based companies. The aim is to generate content through a community consisting of (small) design/textile companies and individual designers aiming to valorize their interactive textiles in the ITL format. Subscriptions and development of physical samples will support maintenance and curation of the platform, thereby providing future users with consistent and reliable content.

\section{Conclusion}

We present the design, development, and evaluation of the Interactive Textile Library (ITL), a digital platform with physical interactive textile samples supporting multi-disciplinary collaboration. The platform provides information about material characteristics, experiential qualities, interactive technology, manufacturing process and support to create and hack samples. Users with diverse expertise, namely interaction designers, textile designers and engineers, can view interactive textiles from their point-of-view, as well as browse different perspectives to better understand the different vocabularies and requirements. Professional (interaction) designers and experts valued the physical samples and videos and suggest that the platform could facilitate incorporation of interactive textiles in design practice by reducing fabrication time of prototypes. 


\section{References}

[1] Anon. Home. Retrieved August 2, 2021 from https://materiom.org/

[2] Anon. How to get what you want. Retrieved August 2, 2021 from https://www.kobakant.at/DIY/

[3] Anon. Materiability research group. Retrieved August 2, 2021 from http://materiability.com/

[4] Anon. Produktentwicklung und MECHATRONIK. Retrieved August 2, 2021 from https://www. vdi.de/tg-fachgesellschaften/vdi-gesellschaftprodukt-und-prozessgestaltung/produktentwicklung-und-mechatronik

[5] Anon. 2017. Soft robotics toolkit. (October 2017). Retrieved August 2, 2021 from https://softroboticstoolkit.com/

[6] Anon.Retrieved August 2, 2021 from https://learn. adafruit.com/

[7] Jason Alexander et al. 2018. Grand challenges in shape-changing interface research. Proceedings of the $2018 \mathrm{CHI}$ Conference on Human Factors in Computing Systems (2018). DOI:http://dx.doi. org/10.1145/3173574.3173873

[8] B\&R WIN CO., LTD. Kleidung mit Sensor. DE 20 2008016426 U 1, 28 May 2009

[9] Bahareh Barati, Elisa Giaccardi, and Elvin Karana. 2018. The making OF Performativity in designing [with] SMART Material Composites. Proceedings of the $2018 \mathrm{CHI}$ Conference on Human Factors in Computing Systems (April 2018), 1-11. DOI:http://dx.doi.org/10.1145/3173574.3173579

[10] Marion Buchenau and Jane Fulton Suri. 2000. Experience prototyping. Proceedings of the conference on Designing interactive systems processes, practices, methods, and techniques - DIS '00 (August 2000), 424-433. DOl:http://dx.doi. org/10.1145/347642.347802

[11] Leah Buechley. 2010. LilyPad Arduino: rethinking the materials and cultures of educational technology. Proceedings of the 9th International Conference of the Learning Sciences 2 (June 2010), 127-128.

[12] Leah Buechley, Nwanua Elumeze, C. Dodson, and Michael Eisenberg. 2005. Quilt snaps: A fabric based computational construction kit. IEEE International Workshop on Wireless and Mobile Technologies in Education (WMTE'05) (2005). DOI:http://dx.doi.org/10.1109/wmte.2005.55

[13] Lina M. Castano and Alison B. Flatau. 2014 Smart fabric sensors and e-textile technologies: A review. Smart Materials and Structures 23, 5 (2014), 053001. DOl:http://dx.doi. org/10.1088/0964-1726/23/5/053001

[14] Daimler AG. Textilelektrode. DE 102008049112 A1, 7 May 2009.

[15] Deutsche Institute für Textil- und Faserforschung (DITF). Kleidungsstück mit integrierter Sensorik. DE 102004030261 A 1, 19 January 2006.

[16] Laura Devendorf, Joanne Lo, Noura Howell, Jung Lin Lee, Nan-Wei Gong, M. Emre Karagozler, Shiho Fukuhara, Ivan Poupyrev, Eric Paulos, and Kimiko Ryokai. 2016. "I don't Want to Wear a Screen": Probing Perceptions of and Possibilities for Dynamic Displays on Clothing. Proceedings of the $2016 \mathrm{CHI}$ Conference on Human Factors in Computing Systems. Association for Computing Machinery, New York, NY, USA, 6028-6039. DOI:https://doi.org/10.1145/2858036.2858192

[17] Haoyu Dong. 2019. Disappearing textile interface with inherent feedforwards. Proceedings of the 11th International Conference on Automotive Use Interfaces and Interactive Vehicular Applications: Adjunct Proceedings (2019). DOI:http://dx.doi. org/10.1145/3349263.3349598

[18] Jiachun Du, Panos Markopoulos, Qi Wang, Marina Toeters, and Ting Gong. 2018. ShapeTex: Implementing Shape-Changing Structures in Fabric for Wearable Actuation. TEl '18: Proceedings of the Twelfth International Conference on Tangible, Embedded, and Embodied Interaction (March 2018), 166-176. DOI:http://dx.doi. org/10.1145/3173225.3173245

[19] Elastic Textile Europe GmbH. Textile Flächenelektrode sowie Kleidungsstück mit einer solchen. DE 102009028314 A1, 10 February 2011.

[20] Aluna Everitt and Jason Alexander. 2017. PolySurface: A Design Approach for Rapid Prototyping of Shape-Changing Displays Using Semi-Solid Surfaces. Proceedings of the 2017 Conference on Designing Interactive Systems (June 2017), 1283-1294. DOl:http://dx.doi. org/10.1145/3064663.3064677

[21] Mikhaila Friske, Shanel Wu, and Laura Devendorf. 2019. AdaCAD: Crafting Software For Smart Textiles Design. Proceedings of the $2019 \mathrm{CHI}$ Conference on Human Factors in Computing Systems (May 2019), 1-13. DOI:http://dx.doi. org/10.1145/3290605.3300575

[22] Inga Gehrke, Vadim Tenner, Volker Lutz, David Schmelzeisen, and Thomas Gries. 2019. Smart textiles production overview of materials, sensor and production technologies for industrial smart textiles, Basel, Switzerland: MDPI.

[23] Gilliland, S., Komor, N., Starner, T., \& Zeagler, C. (2010, October). The textile interface swatchbook: Creating graphical user interface-like widgets with conductive embroidery. In International Symposium on Wearable Computers (ISWC) 2010 (pp. 1-8). IEEE.

[24] Nur Al-huda Hamdan, Simon Voelker, and Jan 
Borchers. 2018. Sketch\&Stitch: Interactive Embroidery for E-textiles. Proceedings of the 2018 $\mathrm{CHI}$ Conference on Human Factors in Computing Systems (April 2018), 1-13. DOI:http://dx.doi. org/10.1145/3173574.3173656

[25] Anja Hertenberger, Barbro Scholz, Beam Contrechoc, Becky Stewart, Ebru Kurbak, Hannah Perner-Wilson, Irene Posch, Isabel Cabral, Jie Qi, Katharina Childs, Kristi Kuusk, Lynsey Calder, Marina Toeters, Marta Kisand, Martijn ten Bhömer, Maurin Donneaud, Meg Grant, Melissa Coleman, Mika Satomi, Mili Tharakan, Pauline Vierne, Sara Robertson, Sarah Taylor, and Troy Robert Nachtigall. 2014. 2013 e-textile swatchbook exchange: the importance of sharing physical work. In Proceedings of the 2014 ACM International Symposium on Wearable Computers: Adjunct Program (ISWC '14 Adjunct). Association for Computing Machinery, New York, NY, USA, 77-81. DOI:https://doi. org/10.1145/2641248.2641276

[26] Dónal P. Holland, Sara Berndt, Maxwell Herman, and Conor J. Walsh. 2018. Growing the soft robotics community through knowledge-sharing initiatives. Soft Robotics 5, 2 (2018), 119-121. DOI:http://dx.doi.org/10.1089/soro.2018.29013. dph

[27] Elaine Igoe. 2010. The tacit-turn: textile design in design research. Duck Journal for Research in Textiles and Textile Design 1 (2010), 1-11.

[28] Elaine Igoe. 2018. Change matters: Theories of postdigital textiles and material design. Proceedings of DRS 2018 International Conference: Catalyst (May 2018), 1787-1799. DOI:http://dx.doi. org/10.21606/drs.2018.621

[29] Infineon Technologies AG. Kleidungsstück mit integrierten elektronischen Komponenten. DE 00 0010350869 A 1, 9 June 2005.
[30] Cristina Isaia, Simon A. McMaster, and Donal McNally. 2020. Study of performance of Knitted Conductive sleeves as Wearable textile STRAIN sensors for joint motion tracking. 2020 42nd Annual International Conference of the IEEE Engineering in Medicine \&amp; Biology Society (EMBC) (August 2020), 4555-4558. DOI:http:// dx.doi.org/10.1109/embc44109.2020.9176429

[31] Lee Jones, Sara Nabil, and Audrey Girouard. 2020. Swatch-bits: Prototyping E-textiles with Modular Swatches. Proceedings of the Fourteenth International Conference on Tangible, Embedded, and Embodied Interaction (February 2020), 893-897. DOI:http://dx.doi. org/10.1145/3374920.3374971

[32] Lee Jones and Audrey Girouard. 2021. Patching Textiles: Insights from Visible Mending Educators on Wearability, Extending the Life of Our Clothes, and Teaching Tangible Crafts. Creativity and Cognition. Association for Computing Machinery, New York, NY, USA, Article 36, 1-11. DOI:https:// doi.org/10.1145/3450741.3465265

[33] Magnus H. Kaspersen, Sebastian Hines, Mark Moore, Majken K. Rasmussen, and Marcelo A. Dias. 2019. Lifting Kirigami Actuators up where they belong. Proceedings of the 2019 on Designing Interactive Systems Conference (June 2019), 935-947. DOl:http://dx.doi. org/10.1145/3322276.3323688

[34] Sofie Kinch, Erik Grönvall, Marianne Graves Petersen, and Majken Kirkegaard Rasmussen. 2014 Encounters on a shape-changing bench. Proceedings of the 8th International Conference on Tangible, Embedded and Embodied Interaction - TEI '14 (February 2014), 233-240. DOI:http:// dx.doi.org/10.1145/2540930.2540947

[35] Jihyun Lee, Da Kim, Sungwoo Chun, Jin Song, Eui Yoo, Jung Kyu Kim, Changhuyn Pang. 2020.
Intrinsically Strain-Insensitive, Hyperelastic Temperature-Sensing fiber withCompressed MicroWrinkles for Integrated Textronics. Advanced Materials Technologies 5, 5 (2020), 2000073. DOI:http://dx.doi.org/10.1002/admt.202000073

[36] Grace Ngai, Stephen C.F. Chan, Joey C.Y. Cheung, and Winnie W.Y. Lau. 2009. The TeeBoard: an education-friendly construction platform for e-textiles and wearable computing. Proceedings of the SIGCHI Conference on Human Factors in Computing Systems (2009), 249-258. DOI:http://dx.doi.org/10.1145/1518701.1518742

[37] H.R. Mattila. 2010. Intelligent textiles and clothing, New Delhi: Oxford.

[38] Mega Elektroniikka Oy; Suunto Oy. Sensoranordnung zum Messen von Signalen auf der Hautoberfläche und Verfahren zur Herstellung der Sensoranordnung. DE 112004001921 T5, 28 August 2008

[39] Militz, D. Textilelektrode. DE 202006007226 U1, 11 October 2007.

[40] Sara Mlakar and Michael Haller. 2020. Design Investigation of Embroidered Interactive Elements on Non-Wearable Textile Interfaces. Proceedings of the $2020 \mathrm{CHI}$ Conference on Human Factors in Computing Systems. Association for Computing Machinery, New York, NY, USA, 1-10. DOI:https:// doi.org/10.1145/3313831.3376692

[41] Sara Mlakar, Mira Alida Haberfellner, Hans-Christian Jetter, and Michael Haller. 2021. Exploring Affordances of Surface Gestures on Textile User Interfaces. Designing Interactive Systems Conference 2021. Association for Computing Machinery New York, NY, USA, 1159-1170. DOI:https://doi. org/10.1145/3461778.3462139

[42] OFA Bamberg GmbH. Faden zur Ermittlung der Zugspannung, insbesondere in einem med- 
izinischen Gestrick oder Gewirk. DE 102008003 122 A 1, 9 July 2009.

[43] Jifei Ou, Mélina Skouras, Nikolaos Vlavianos, Felix Heibeck, Chin-Yi Cheng, Jannik Peters, and Hiroshi Ishii. 2016. AeroMorph - Heat-sealing Inflatable Shape-change Materials for Interaction Design. In Proceedings of the 29th Annual Symposium on User Interface Software and Technology (UIST '16). Association for Computing Machinery, New York, NY, USA, 121-132. DOI:https:// doi.org/10.1145/2984511.2984520

[44] Isabel P. Qamar, Rainer Groh, David Holman, and Anne Roudaut. 2018. HCl meets material science. Proceedings of the $2018 \mathrm{CH}$ Conference on Human Factors in Computing Systems (April 2018), 1-23. DOI:http://dx.doi. org/10.1145/3173574.3173948 Ivan Poupyrev, Nan-Wei Gong, Shiho Fukuhara, Mustafa E. Karagozler, Carsten Schwesig, Karen E. Robinson (2016). Project Jacquard. Proceedings of the $2016 \mathrm{CHI}$ Conference on Human Factors in Computing Systems. https://doi. org/10.1145/2858036.2858176

[45] Isabel Qamar, Rainer Groh, David Holman, and Anne Roudaut. 2019. Bridging the gap between material science and human-computer interaction. Interactions 26, 5 (2019), 64-69. DOI:http:// dx.doi.org/10.1145/3344943

[46] Majken K. Rasmussen, Esben W. Pedersen, Marianne G. Petersen, and Kasper Hornbæk. 2012. Shape-changing interfaces: A Review of the Design Space and Open Research Questions. Proceedings of the SIGCHI Conference on Human Factors in Computing Systems (2012). DOI:http://dx.doi.org/10.1145/2207676.2207781

[47] Material connexion // every idea has a material solution. ${ }^{\circledR}$. Material ConneXion. (n.d.). Retrieved from https://materialconnexion.com/.
[48] Michael L. Rivera, Jack Forman, Scott E. Hudson, and Lining Yao. 2020. Hydrogel-Textile Composites: Actuators for Shape-Changing Interfaces. CHI EA '20: Extended Abstracts of the 2020 $\mathrm{CHI}$ Conference on Human Factors in Computing Systems (April 2020), 1-9. DOl:http://dx.doi. org/10.1145/3334480.3382788

[49] Michael L. Rivera, Melissa Moukperian, Danie Ashbrook, Jennifer Mankoff, and Scott E. Hudson 2017. Stretching the bounds of $3 d$ printing with embedded textiles. $\mathrm{CHI}$ '17: Proceedings of the 2017 CHI Conference on Human Factors in Computing Systems (May 2017), 497-508. DOI:http:// dx.doi.org/10.1145/3025453.3025460

[50] Anne Roudaut. Retrieved from http://www.morphui.com/

[51] Vanessa Sanchez, Conor J. Walsh, and Robert J. Wood. 2020. Textile Technology for Soft Robotic and Autonomous Garments. Advanced Functional Materials 31, 6 (December 2020), 2008278. DOI:http://dx.doi.org/10.1002/adfm. 202008278

[52] Elizabeth B.-N. Sanders. 2005. Information, Inspiration and Co-creation. 6th International Conference of the European Academy of Design (March 2005).

[53] David Schmelzeisen, Hannah Koch, Chris Pastore, and Thomas Gries. 2017. 4D Textiles: Hybrid Textile structures that can CHANGE structural form with time by $3 d$ printing. Narrow and Smart Textiles (2017), 189-201. DOI:http://dx.doi. org/10.1007/978-3-319-69050-6_17

[54] W.B. Spillman, J.S. Sirkis, and P.T. Gardiner. 1996. Smart materials and structures: What are they? Smart Materials and Structures 5, 3 (1996), 247-254. DOI:http://dx.doi.org/10.1088/0964$1726 / 5 / 3 / 002$

[55] Jeanne Tan, Anne Toomey, and Annie Warbur- ton. 2018. CraftTech: Hybrid frameworks FOR textile-based PRACTICE. Journal of Textile Engineering \&amp; Fashion Technology 4, 2 (June 2018). DOI:http://dx.doi.org/10.15406/ jteft.2018.04.00135

[56] Sarah Taylor and Sara Robertson. 2014. Digital lace. Proceedings of the 2014 ACM International Symposium on Wearable Computers Adjunct Program - ISWC '14 Adjunct (2014), 93-97. DOI:http://dx.doi.org/10.1145/2641248.2641280

[57] Riikka Townsend, Anne Louise Bang, and Jussi Mikkonen. 2020. Textile designer perspective on haptic interface design: A sensorial platform for conversation between discipline. Distributed, Ambient and Pervasive Interactions 12203 (July 2020), 110-127. DOI:http://dx.doi. org/10.1007/978-3-030-50344-4_9

[58] Daniela Ghanbari Vahid, Lee Jones, Audrey Girouard, and Lois Frankel. 2021. Shape changing FABRIC samples for interactive fashion design. TEl '21: Fifteenth International Conference on Tangible, Embedded, and Embodied Interaction (February 2021), 1-7. DOI:http://dx. doi org/10.1145/3430524.3440633

[59] Louise Valentine, Jen Ballie, Joanna Bletcher, Sara Robertson, and Frances Stevenson. 2017. Design thinking for textiles: Let's make it meaningful. The Design Journal 20, sup1 (2017). DOI:http://dx.doi.org/10.1080/14606925.2017.13 53041

[60] Anna Vallgårda and Johan Redström. 2007. Computational composites. Proceedings of the SIGCHI Conference on Human Factors in Computing Systems (2007). DOI:http://dx.doi. org/10.1145/1240624.1240706

[61] Lisa Wastiels and Ine Wouters. 2008. Material Considerations in Architectural Design: A study 
of the aspects identified by architects for selecting materials. . Conference: Proceedings of DRS 2008 (July 2008).

[62] Mikael Wiberg. 2018. The material turn. The Materiality of Interaction (2018). DOI:http://dx.doi. org/10.7551/mitpress/9780262037518.003.0003

[63] Amy Winters. 2016. Building a soft machine: New modes of expressive surfaces. Design, User Experience, and Usability: Technological Contexts (June 2016), 401-413. DOl:http://dx.doi. org/10.1007/978-3-319-40406-6_39

[64] Linda Worbin. 2010. Designing dynamic textile patterns. Ph.D. Dissertation. Göteborg, Chalmers University of Technology.

[65] Shanel Wu and Laura Devendorf. 2020. Unfabricate: Designing Smart Textiles for Disassembly. In Proceedings of the $2020 \mathrm{CHI}$ Conference on Human Factors in Computing Systems (CHI '20). Association for Computing Machinery, New York, NY, USA, 1-14. DOI:https://doi. org/10.1145/3313831.3376227

[66] Lining Yao, Ryuma Niiyama, Jifei Ou, Sean Follmer, Clark Della Silva, and Hiroshi Ishii. 2013. PneUI: pneumatically actuated soft composite materials for shape changing interfaces. In Proceedings of the 26th annual ACM symposium on User interface software and technology (UIST '13). Association for Computing Machinery, New York, NY, USA, 1322. DOI:https://doi.org/10.1145/2501988.2502037

[67] Lining Yao, Jifei Ou, Chin-Yi Cheng, Helene Steiner, Wen Wang, Guanyun Wang, and Hiroshi Ishii. 2015. BioLogic: Natto Cells as Nanoactuators for Shape Changing Interfaces. In Proceedings of the 33rd Annual ACM Conference on Human Factors in Computing Systems (CHI '15). Association for Computing Machinery, New York, NY, USA, 1-10. DOI:https://doi.org/10.1145/2702123.2702611 